\title{
Tuning of Ag-SPR band position in refractive index controlled inorganic-organic hybrid $\mathrm{SiO}_{2}-\mathrm{PEO}-\mathrm{TiO}_{2}$ films $^{\dagger}$
}

\author{
SAMAR KUMAR MEDDA, MOUMITA MITRA and GOUTAM DE* \\ Sol-Gel Division, Central Glass and Ceramic Research Institute, 196, Raja S C Mullick Road, \\ Kolkata 700032 \\ e-mail: gde@cgcri.res.in
}

\begin{abstract}
Inorganic (silica-titania)-organic (polyethylene oxide) hybrid films with variable refractive index (RI) values were synthesized and Ag nanoparticles were generated in situ inside such hybrid films to develop coloured coatings specially on plastic substrates. The hybrid films and the corresponding Agincorporated films were prepared from sols derived from a mixture of silicon tetraethoxide (STE), 3(glycidoxypropyl)trimethoxysilane (GPTMS), titanium tetraisopropoxide (TTIP) and silver nitrate following a sol-gel dip-coating method and cured at low temperature $\left(90^{\circ} \mathrm{C}\right)$, followed by UV treatment with an energy equivalent to $5 \cdot 3 \pm 0 \cdot 1 \mathrm{~J} \mathrm{~cm}^{-2}$. The equivalent $\mathrm{SiO}_{2}: \mathrm{SiO}_{1.5}\left(\mathrm{CH}_{2}\right)_{3} \mathrm{OCH}_{2} \mathrm{CH}\left(\mathrm{CH}_{2}\right) \mathrm{O}$ : $\mathrm{TiO}_{2}:$ Ag molar ratios (nominal) of the final cured films are varied in the ranges $(67 \cdot 9-0): 29 \cdot 1:(0-$ $67.9): 3$. The refractive index values of the cured hybrid films were found to be increased systematically from 1.475 to 1.710 with increasing Ti-component. The Ag-SPR peak, in case of silica-polyethylene oxide host $(\mathrm{RI}=1.475)$, observed at $419 \mathrm{~nm}$, gradually red-shifted to $497 \mathrm{~nm}$ upon increasing the Ticomponent (equivalent $\mathrm{TiO}_{2}$ content $67.9 \mathrm{~mol} \%$; $\mathrm{RI}=1.710$ ) of the film. As a consequence, a systematic change of Ag-SPR position yielded yellow, yellowish-orange, orange, brownish-orange and orangishbrown coloured coatings.
\end{abstract}

Keywords. Ag-plasmon tuning; inorganic-organic hybrids; refractive index tailoring; coloured coatings; sol-gel.

\section{Introduction}

Inorganic-organic hybrid composite films derived from alkoxides and molecular hybrids (functional alkoxides) having different refractive index (RI) values are important materials and useful in developing abrasion resistant, reflecting and antireflecting films particularly on soft materials like plastics at low temperature $\left(<100^{\circ} \mathrm{C}\right) .{ }^{1-7}$ These coatings can also be decorated with different colours using the noble metal nanoparticles as colouring sources. ${ }^{8-10}$

Very recently we described a simple yet much improved technology for the development of inorganic-organic hybrid nanocomposite sols applicable for making hard and abrasion resistant coatings curable at low temperature $\left(<100^{\circ} \mathrm{C}\right)$ on plastic substrates. ${ }^{4,5,11}$ The incorporation of $\mathrm{Au}^{8}$ and $\mathrm{Ag}^{9}$ nanoparticles inside the inorganic-organic hybrid matrices could produce uniform colouration arising from the SPR absorption of embedded nanoparticles. Recently we have shown controlled coarsening phenomena of

${ }^{\dagger}$ Dedicated to Prof. C N R Rao on his 75th birthday

*For correspondence
Ag nanoparticles in a silica-polyethylene oxide $\left(\mathrm{SiO}_{2}-\right.$ PEO) hybrid matrix by UV light of different energies. ${ }^{12}$ This leads to change in optical properties of the Ag nanoparticles while embedding in the hybrid matrix. We have also shown plasmon coupling of $\mathrm{Au}$ nanoparticles embedded in a $\mathrm{SiO}_{2}-\mathrm{PEO}-\mathrm{TiO}_{2}$ hybrid film matrix leading to the shifting of Au plasmon bands with respect to the UV treatment energies. ${ }^{10}$ Previously, we have successfully tailored the surface plasmon absorption positions of $\mathrm{Au}$ and $\mathrm{Ag}$ nanoparticles by tuning the RI of the embedding dielectric films $\left(\mathrm{SiO}_{2}, \mathrm{SiO}_{2}-\mathrm{TiO}_{2}{ }^{13}\right.$ and $\left.\mathrm{SiO}_{2}-\mathrm{ZrO}_{2}{ }^{14,15}\right)$ applicable for glass substrates. These films were prepared after heat-treatment of the doped films at high temperatures $\left(500-800^{\circ} \mathrm{C}\right)$.

In this work, we attempted to synthesize low temperature $\left(<100^{\circ} \mathrm{C}\right) / \mathrm{UV}$ curable inorganic-organic hybrid $\left(\mathrm{SiO}_{2}-\mathrm{PEO}-\mathrm{TiO}_{2}\right)$ coatings having different RI values, and tunable coloured coatings using dispersed Ag nanoparticles of fixed molar concentration in these refractive index controlled composite inorganicorganic hybrid films. Main aim of this work was therefore to study the effect of the matrix RI on the optical properties of $\mathrm{Ag}$ nanoparticles, leading to the 
generation of different colours useful for decorative coloured coatings on plastic substrates. The formation of $\mathrm{Ag}$ nanoparticles in the inorganic-organic coating matrices were monitored by UV-visible, FTIR and transmission electron microscopy.

\section{Experimental}

\subsection{Preparation of sols}

All chemicals were used as received. Silicon tetraethoxide (STE), 3-(glycidoxypropyl)trimethoxysilane (GPTMS) and titanium tetraisopropoxide (TTIP) were supplied by Sigma-Aldrich, while $\mathrm{AgNO}_{3}, n$ butanol, $\mathrm{HNO}_{3}$ and acetylacetone (acac) were obtained from s.d. fine-chem limited. Aluminum acetylacetonate $\left(\mathrm{Al}(\mathrm{acac})_{3}\right)$ was supplied by Lancaster.

First of all, undoped hybrid sols were prepared using STE, GPTMS, TTIP, acac, $\mathrm{Al}(\mathrm{acac})_{3}$ (catalytic amount as epoxy polymerization initiator), $n$-butanol, water and catalytic amount of $\mathrm{HNO}_{3}$. The alkoxides STE, GPTMS, TTIP were used in different mol ratios (table 1) in order to obtain different compositions in the final cured coatings. First, TTIP-acac solution was prepared by stirring $(30 \mathrm{~min})$ the required amount of TTIP with acac $(0.5 \mathrm{~mol}$ per Ti-alkoxide) in $n$-butanol (one-third of total amount). STE, GPTMS and TTIP-acac solution in required proportions were then mixed with $n$-butanol (one-third of total amount) by stirring and refluxed for $30 \mathrm{~min}$ in order to obtain a homogeneous mixed solution. The solution was then cooled to room temperature. Acidulated water dissolved in $n$-butanol (remaining one-third) was then added with stirring and stirring was continued for another $1 \mathrm{~h} .5 \times 10^{-4} \mathrm{~mol} \mathrm{HNO}_{3}$ and $0.5 \mathrm{~mol}$ water per mol of alkoxy group were used for hydrolysis/condensation reactions. The epoxy polymerizing agent $\mathrm{Al}(\mathrm{acac})_{3}(0.05 \mathrm{~mol}$ per mol of GPTMS $)$ was added at this stage with stirring till dissolve. The resulting clear sols with 5 different compositions as shown in table 1 were then used for Ag doping.

Table 1. Mole ratios of different alkoxides used to prepare inorganic-organic hybrid sols.

Sample label

(undoped sol) STE (mol) GPTMS (mol) TTIP (mol)

\begin{tabular}{llll}
\hline SGT730 & 7 & 3 & 0 \\
SGT433 & 4 & 3 & 3 \\
SGT235 & 2 & 3 & 5 \\
SGT136 & 1 & 3 & 6 \\
SGT037 & 0 & 3 & 7 \\
\hline
\end{tabular}

The equivalent oxide $\left(\mathrm{SiO}_{2}+\mathrm{SiO}_{1.5}-\mathrm{PEO}+\mathrm{TiO}_{2}\right) \mathrm{wt} \%$ (solid content) in the sols was in the range of 10 $14 \%$. The molar ratio of the $\mathrm{Ag}$ metal to the oxide $\left(\mathrm{SiO}_{2}+\mathrm{SiO}_{1.5}-\mathrm{PEO}+\mathrm{TiO}_{2}\right)$ was kept constant in all the sols, being 3 equivalent $\mathrm{mol} \% \mathrm{Ag}-97 \%$ hybrid matrix $\left(\mathrm{SiO}_{2}+\mathrm{SiO}_{1.5}-\mathrm{PEO}+\mathrm{TiO}_{2}\right)$. The calculated amount of $\mathrm{AgNO}_{3}$ was dissolved in water (molar ratio of water to $\mathrm{AgNO}_{3}$ can be varied from 26 to 28) and added to the corresponding undoped sols with stirring. Clear colourless sols thus obtained were used for the preparation of films.

\subsection{Preparation of films}

The inorganic-organic hybrid matrix films were deposited on cleaned Si-wafer (one side polished) substrates. The Ag-doped films were deposited on polycarbonate (PC) sheet (plastic), soda-lime glass, silica glass and also on Si-wafer substrates. Prior to the film deposition, the substrates were cleaned with neutral detergent, rinsed with double distilled water and finally with hot isopropanol. The coatings were prepared using the dipping technique (Dip-master 200, Chemat Corporation) with withdrawal velocities in the range $2-3$ inch $\mathrm{min}^{-1}$. The as-prepared films were dried at $60^{\circ} \mathrm{C}$ for $30 \mathrm{~min}$ and followed by $90^{\circ} \mathrm{C}$ for $1 \mathrm{~h}$. The dried film was then subjected to UV-treatment. The UV treatment was done by passing the dried film samples through a conveyorized UV curing machine fitted with a high power $(5000 \mathrm{~W})$ medium pressure $\mathrm{Hg}$ vapor lamp emitting a range of wavelengths from $200-400 \mathrm{~nm}$ with maximum intensity peaks in the UV-A region (300$380 \mathrm{~nm}$ ). In a single UV treatment operation, the sample receives $\sim 2.65 \mathrm{~J} \mathrm{~cm}^{-2}$ energy (UV-A) and the UV treatment of the film was done two times for each surface (UV energy per surface $5 \cdot 3 \pm 0 \cdot 1 \mathrm{~J} \mathrm{~cm}^{-1}$ ) in a cumulative manner. The UV energy was monitored using a UV intensity meter (UV Power Puck, EIT), passing through the conveyor along with the sample.

The films deposited on both-side polished silicon wafers (intrinsic; IR transparent) are used for the IR spectral studies. The undoped matrix films on oneside polished silicon wafers were used for the RI measurements.

\subsection{Characterization}

Refractive index values of the thermal $\left(90^{\circ} \mathrm{C} / 1 \mathrm{~h}\right)$, and followed by UV cured $\left(5.3 \mathrm{~J} \mathrm{~cm}^{-2}\right)$ hybrid un- 
doped films are measured using a Gaertner Ellipsometer (model L116B) at $632.8 \mathrm{~nm}$. The thickness of the Ag-incorporated films was measured by a Surfcorder SE-2300 profilometer (Kosaka Laboratory Ltd., Japan). The UV-visible spectra of the Agdoped films were obtained using a Cary 50 scan spectrophotometer. Infrared absorption spectra of the films deposited on silicon wafers were recorded by FTIR spectrometry (Nicolet, model 5PC) with a resolution of $4 \mathrm{~cm}^{-1}$ and 32 scans. Transmission electron microscopic (TEM) measurement was carried out with a JEOL 2010 transmission electron microscope. TEM sample was prepared by scraping the respective UV-treated films. The scraped film was first dispersed in methanol under ultrasonication, and one small drop of this dispersion was deposited onto a carbon-coated copper grid on an underlying tissue paper.

\section{Results and discussion}

In order to obtain different refractive index values of the films the equivalent mole ratio of $\mathrm{SiO}_{2}, \mathrm{SiO}_{1.5}$ $\left(\mathrm{CH}_{2}\right)_{3} \mathrm{OCH}_{2} \mathrm{CH}\left(\mathrm{CH}_{2}\right) \mathrm{O}$ (designated as ' $\mathrm{SiO}$ 1.5 $-\mathrm{PEO}$ ') and $\mathrm{TiO}_{2}$ (high refractive index component) was varied using STE (source of $\mathrm{SiO}_{2}$ ), GPTMS (source of $\mathrm{SiO}_{1.5}-\mathrm{PEO}$ ) and TTIP (source of $\mathrm{TiO}_{2}$ ) (table 1). It may be noted here that the hybrid precursor GPTMS has both polymerizable alkoxy groups as well as epoxy group bonded with $\mathrm{Si}$ through $-\left(\mathrm{CH}_{2}\right)_{3}-\mathrm{O}$ chain. So the hydrolysis/condensation reactions of the alkoxy groups produce $-\mathrm{Si}-\mathrm{O}-\mathrm{Si}-$ network whereas the epoxy group generates polyethylene oxide (PEO) network after polymerization. As a result, the hybrid end product as shown in scheme 1 is expected to form from GPTMS after hydrolysis-condensation reactions and polymerization of epoxy groups.

Clearly the hybrid end product obtained from GPTMS has polyethylene oxide (PEO) linkages bonded with the silica network. Three -Si-O- linkages are shown in the hybrid end product; each of these will be shared with another Si atom. For this reason this composite hybrid unit has been designated as $\mathrm{SiO}_{1.5}\left(\mathrm{CH}_{2}\right)_{3} \mathrm{OCH}_{2} \mathrm{CH}\left(\mathrm{CH}_{2}\right) \mathrm{O}$ or $\mathrm{SiO}_{1.5}-\mathrm{PEO}$. The

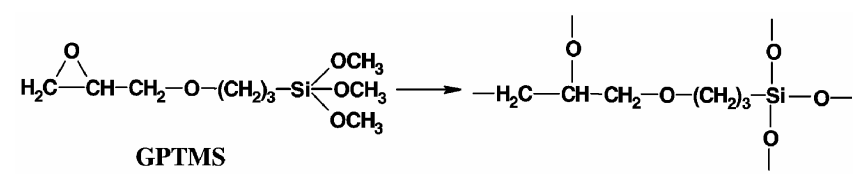

Scheme 1.
STE, GPTMS and TTIP originated alkoxy groups, during the co-hydrolysis/condensation reactions would covalently connect each other in a molecular level through $-\mathrm{Si}-\mathrm{O}-\mathrm{Si}-$ and $-\mathrm{Si}-\mathrm{O}-\mathrm{Ti}-$ linkages. The GPTMS originated epoxy groups would polymerize during the thermal $\left(90^{\circ} \mathrm{C}\right) / \mathrm{UV}$-treatment of the films obtained from these sols and eventually a very homogeneous interconnecting inorganic-organic hybrid composite network would be formed after the final curing of the films.

The undoped films prepared by a single dipping technique appear optically transparent and homogeneous after the thermal, and followed by UV curing with an energy equivalent to $5.3 \mathrm{~J} \mathrm{~cm}^{-2}$. As expected, after curing of the coatings, the refractive index values are increasing with increasing Ti-component (table 2). All Ag doped films were also clear and transparent. All films showed very uniform intense colouration after the final UV curing. The nominal compositions of the Ag-doped hybrid films and the corresponding Ag-SPR positions leading to formation of different colours are presented in table 3 . The coating thickness of the thermal $\left(90^{\circ} \mathrm{C}\right)$, followed by UV-treated $\left(5.3 \mathrm{~J} \mathrm{~cm}^{-2}\right)$ films, estimated by a profilometer, was in the $250-550 \mathrm{~nm}$ range. The thickness of the highest titania containing film (AgSGT037; see table 3) was kept relatively low to avoid cracking problems after UV-treatment. The adhesion of the films with the substrate is found to be excellent. The pencil hardness value (measured following the specifications of ASTM D 3363) of the final cured films is greater than $3 \mathrm{H}$ when applied on polycarbonate substrates.

To understand the chemical structure of the films FTIR studies were undertaken. Figure 1 shows the FTIR spectral evolution of (as-prepared, $90^{\circ} \mathrm{C}$ and UV-treated) $\mathrm{Ag}$ incorporated hybrid films in four different panels marked by a-d. FTIR of as-prepared Ag-SGT730 film (figure la) shows peaks corresponding to $\mathrm{Si}-\mathrm{O}-\mathrm{Si}$ (asymmetric stretch) at

Table 2. Refractive index values of the thermal $\left(90^{\circ} \mathrm{C} / 1 \mathrm{~h}\right)$ and UV-treated $\left(5 \cdot 3 \pm 0 \cdot 1 \mathrm{~J} \mathrm{~cm}^{-1}\right)$ undoped inorganic-organic films.

\begin{tabular}{lc}
\hline $\begin{array}{l}\text { Sample label } \\
\text { (undoped film) }\end{array}$ & $\begin{array}{c}\mathrm{RI} \pm 0 \cdot 002 \\
\text { (measured at 632.8 nm) }\end{array}$ \\
\hline SGT730 & 1.475 \\
SGT433 & 1.569 \\
SGT235 & 1.650 \\
SGT136 & 1.683 \\
SGT037 & 1.710 \\
\hline
\end{tabular}


Table 3. Nominal compositions of the thermal $\left(90^{\circ} \mathrm{C} / 1 \mathrm{~h}\right)$, followed by and UV-treated $\left(5 \cdot 3 \pm 0 \cdot 1 \mathrm{~J} \mathrm{~cm}^{-1}\right) \mathrm{Ag}$ doped films, along with their colour and SPR peak positions.

\begin{tabular}{lcclc}
\hline $\begin{array}{l}\text { Sample label } \\
\text { Ag doped film) }\end{array}$ & $\begin{array}{c}\text { Film composition } \\
\left(\begin{array}{c}\text { (nominal) after curing }(\mathrm{mol} \text { ratio }) \\
\left(\mathrm{SiO}_{2}: \mathrm{SiO}_{1.5}-\mathrm{PEO}: \mathrm{TiO}_{2}: \mathrm{Ag}\right)\end{array}\right.\end{array}$ & $\begin{array}{c}\text { Film thickness } \\
\text { after curing }(\mathrm{nm})\end{array}$ & Film colour & $\begin{array}{c}\text { Ag-SPR } \\
\text { position }(\mathrm{nm})\end{array}$ \\
\hline Ag-SGT730 & $67 \cdot 9: 29 \cdot 1: 0: 3$ & $550 \pm 10$ & Deep yellow & 419 \\
Ag-SGT433 & $38 \cdot 8: 29 \cdot 1: 29.1: 3$ & $500 \pm 10$ & Yellowish-orange & 443 \\
Ag-SGT235 & $19 \cdot 4: 29 \cdot 1: 48 \cdot 5: 3$ & $450 \pm 10$ & Orange & 460 \\
Ag-SGT136 & $9 \cdot 7: 29 \cdot 1: 58 \cdot 2: 3$ & $400 \pm 10$ & Brownish-orange & 480 \\
Ag-SGT037 & $0: 29.1: 67 \cdot 9: 3$ & $250 \pm 10$ & Orangish-brown & 497 \\
\hline
\end{tabular}

$1085 \mathrm{~cm}^{-1}, \mathrm{Si}-\mathrm{OH}$ at $945 \mathrm{~cm}^{-1}, 7,8,12$ epoxide ring vibrations at 910 and $855 \mathrm{~cm}^{-1}$ (weak), ${ }^{16,17} \mathrm{Si}-\mathrm{O}-\mathrm{Si}$ (symmetric stretch) at $795 \mathrm{~cm}^{-1}$ and $448 \mathrm{~cm}^{-1} \cdot 7,8,12$ Absence of any $\mathrm{NO}_{3}$ vibration at $1385 \mathrm{~cm}^{-1}$ indicates decomposition of $\mathrm{AgNO}_{3}$ at the sol stage. ${ }^{9}$ In case of the thermal $\left(90^{\circ} \mathrm{C}\right)$ and UV-cured $\mathrm{Ag}$ SGT730 films all bands remain unaffected except, the $\mathrm{Si}-\mathrm{O}-\mathrm{Si}$ asymmetric stretch and epoxide bands (figure 1a). The former ( $\mathrm{Si}-\mathrm{O}-\mathrm{Si}$ asym. stretch) has been shifted to $1070 \mathrm{~cm}^{-112}$ where as the later peaks (910 and $855 \mathrm{~cm}^{-1}$ ) are gradually weakened and almost disappeared after UV curing due to the polymerization of epoxy groups to polyethylene oxide. ${ }^{16,17}$ FTIR spectra of three representative Ti-containing films (Ag-SGT433, Ag-SGT235 and Ag-SGT037) are presented in panels $\mathrm{b}, \mathrm{c}$ and $\mathrm{d}$ of figure 1 respectively. As acac has been used to control the fast hydrolysis rate of Ti-alkoxide, FTIR spectra of all asprepared and cured Ti-containing films showed a pair of peaks at 1585 and $1530 \mathrm{~cm}^{-1}$ due to $\mathrm{C}-\mathrm{C}+$ C-O stretching ${ }^{18,19}$ arising from Ti-acac chelate (figures $2 \mathrm{~b}-\mathrm{d})$. The presence of bands in the 1385$1260 \mathrm{~cm}^{-1}$ region attributed to the $\mathrm{Ti}-\mathrm{O}-\mathrm{C}$ vibrations, also supports that acac is bonded to Ti as chelating ligand (figures $1 \mathrm{~b}-\mathrm{d}$ ). ${ }^{20}$ The intensities of acac related peaks are gradually weakened during thermal $\left(90^{\circ} \mathrm{C}\right)$ and UV-treatment of the films indicating decomposition of Ti-acac chelates. FTIR of all UV-treated Ti-containing films show a weak peak around $1718 \mathrm{~cm}^{-1}$ (marked by arrows in figures $\mathrm{lb}-\mathrm{d}$ ) indicating presence of free $\mathrm{C}=\mathrm{O}$ groups $^{21}$ in the films. This result indicates opening of acac chelates occur through a monodentate acac species. The epoxy related vibrations in all these cases are not clearly visible due to overlapping with other peaks. All Ti-containing films show (figures $1 \mathrm{~b}-\mathrm{d}$ ) peaks near 1200 (marked by 1) 1095 (marked by 2), 1040 (marked by 3) and $930 \mathrm{~cm}^{-1}$ (marked by 4) due to $\mathrm{Si}-\mathrm{C}-\mathrm{C}, \mathrm{Si}-\mathrm{O}-\mathrm{Si}, \mathrm{Si}-\mathrm{O}-\mathrm{Si}+$ some contributions of $\mathrm{Si}-\mathrm{O}-\mathrm{Ti}$ and $\mathrm{Si}-\mathrm{O}-\mathrm{Ti}$ vibrations respectively. The relative intensities of later two bands (marked by 3 and 4) are found to be intensified marginally after thermal and UV curing (see the spectra of higher Ticontent films Ag-SGT235 and Ag-SGT037). This observation suggests formation of more $\mathrm{Si}-\mathrm{O}-\mathrm{Ti}$ during the curing stages. It may also be noted here that the $\mathrm{Si}-\mathrm{O}-\mathrm{Si}$ symmetric stretching appeared at $795 \mathrm{~cm}^{-1}$ (see line marked by 5 in figure 1 ) in case of Ag-SGT730 (without Ti-component) film is gradually weakened and almost absent in case of AgSGT037 after UV-curing. This also supports indirectly the formation of $\mathrm{Si}-\mathrm{O}-\mathrm{Ti}$ linkages. It is, therefore, clear from FTIR studies that the modification of refractive index values of the silicapolyethylene oxide-titania hybrid films is arising from uniform composite structure having $\mathrm{Si}-\mathrm{O}-\mathrm{Si}$, $\mathrm{Si}-\mathrm{C}-\mathrm{C}$ and $\mathrm{Si}-\mathrm{O}-\mathrm{Ti}$ inter connecting network. A systematic increase of refractive index with increase of $\mathrm{Ti}$ content also suggests formation of uniform $\mathrm{Si}-\mathrm{O}-\mathrm{Ti}$ network in the mixed films.

The evolution of Ag nanoparticles in the coating matrices is monitored using UV-visible spectroscopy and results of three representative systems (Ag-SGT730, Ag-SGT443 and Ag-SGT037) are presented in figures $2(\mathrm{a}-\mathrm{c})$. The as-prepared $\mathrm{Ag}$ SGT730 film is colourless and showed no absorption peak (figure $2 a$ ) in the visible wavelength region. This result indicates $\mathrm{Ag}$ remains in the asprepared coating matrix as an ionic species $\left(\mathrm{Ag}^{+}\right)$. The formation of Ag nanoparticles have been started when this film is dried at $60^{\circ} \mathrm{C}$; as a result of this Ag-SPR peak at $419 \mathrm{~nm}$ starts to appear and intensifies further at $90^{\circ} \mathrm{C}$. The UV-cured film showed a strong Ag-SPR absorption at $419 \mathrm{~nm}$ (figure 2a) and the film shows intense yellow colouration. In case of Ag-SGT443, the thermal $\left(90^{\circ} \mathrm{C}\right)$ cured film showed no characteristic Ag-SPR (figure 2b). In this case interference related weak peaks are observed due to the difference in RI values of the film and the substrate. UV curing of this film causes generation of 
Ag nanoparticles in the hybrid matrix, and as a result a strong Ag-SPR peak has been observed at $443 \mathrm{~nm}$ (figure 2b). Similar features have also been observed in cases of other Ti-containing films up to the thermal curing stages, and only after the UVtreatment the Ag-SPR peak of the respective films are observed at 460 (Ag-SGT235), 480 (Ag-SGT136) and $497 \mathrm{~nm}$ (Ag-SGT037). The continuous red-

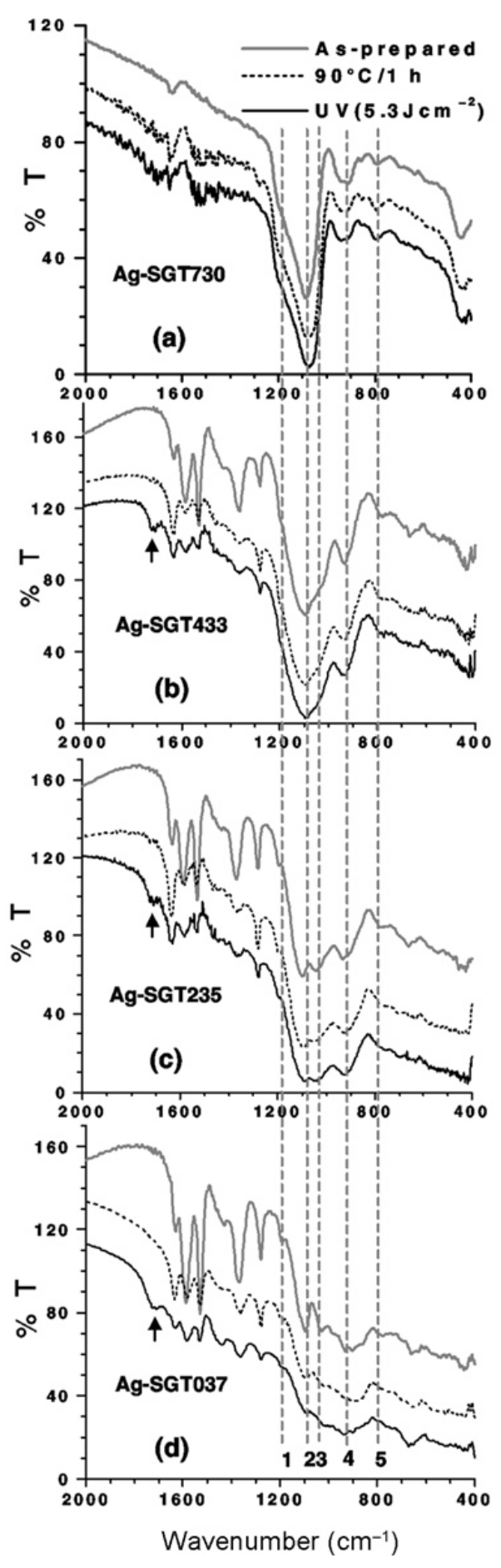

Figure 1. FTIR spectral evolution of Ag incorporated hybrid films under different conditions: (a) Ag-SGT730, (b) Ag-SGT433, (c) Ag-SGT730 and (d) Ag-SGT073. Films were deposited on double side-polished (intrinsic, IR transparent) Si wafers.

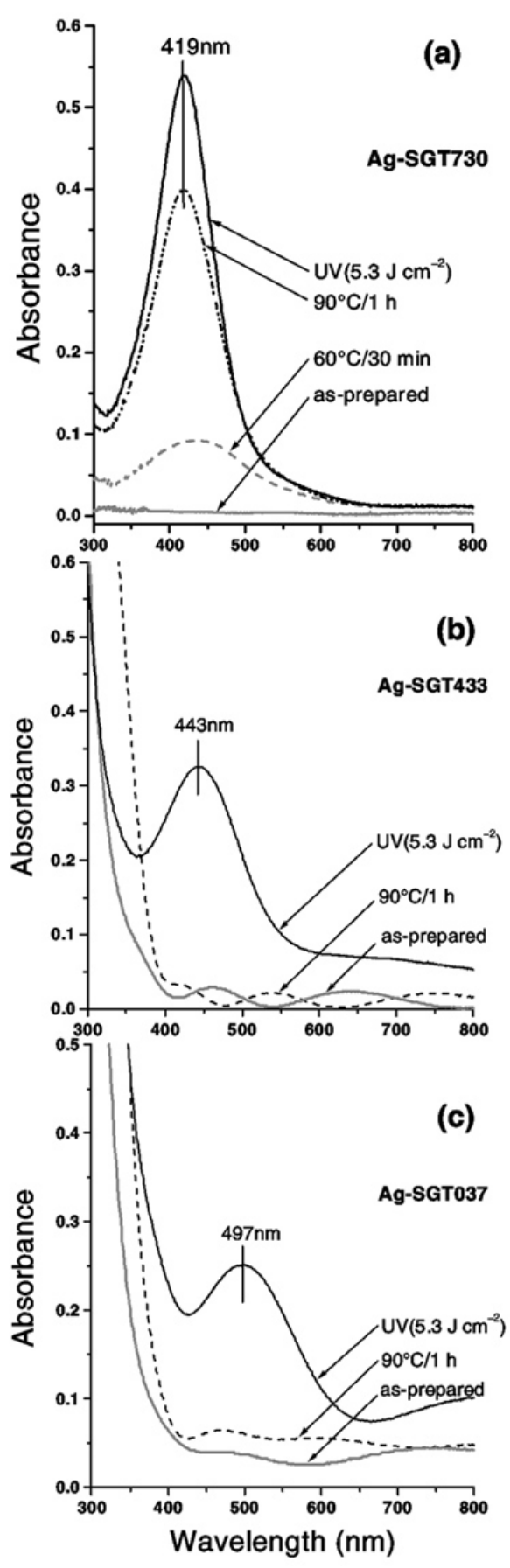

Figure 2. Optical spectral evolution during the formation of Ag nanoparticles: (a) Ag-SGT730, (b) Ag-SGT433 and (c) Ag-SGT073. The films were deposited on silica glass substrates and both sides of the substrate were coated. Thickness of the final UV-treated $\left(5 \cdot 3 \pm 0 \cdot 1 \mathrm{~J} \mathrm{~cm}^{-1}\right)$ films are given in table 3 . 
shifting of the Ag-SPR position is due to the gradual increase of the high index Ti-component leading to a systematic increase of RI values of the hybrid film matrices (see table 2). The spectral evolution of AgSGT037 film showing the appearance of Ag-SPR peak at $497 \mathrm{~nm}$ after UV-curing is presented in figure $2 \mathrm{c}$

Figure 3a shows the optical absorption spectra of all the film compositions (table 3 ) after the final UV curing. The shifting of Ag-SPR from $419 \mathrm{~nm}$ to $497 \mathrm{~nm}$ is clearly seen on going from Ag-SGT730
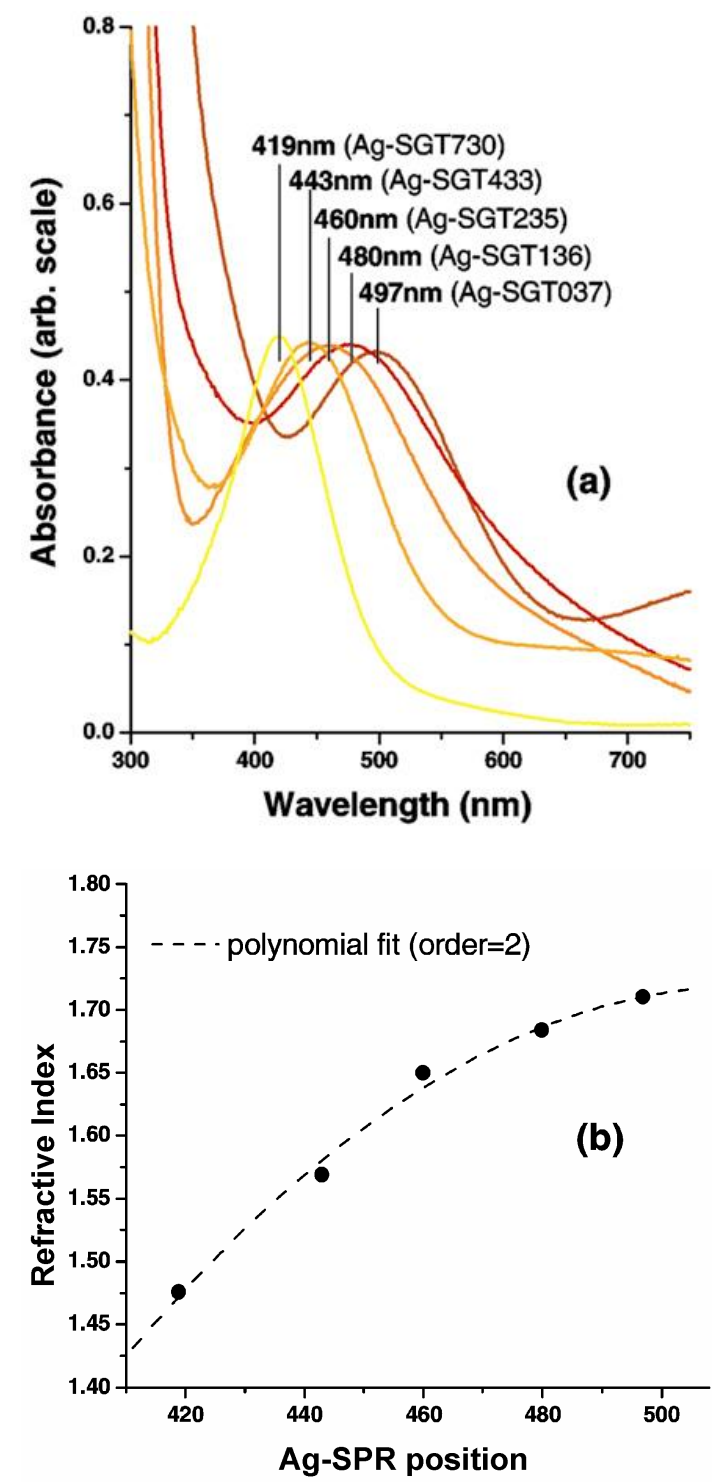

Figure 3. (a) UV-visible spectra of Ag-incorporated hybrid films after the final UV-treatment. The line colours are of close resemblance to that of the original colour of the films and (b) Plot showing the refractive index of the hybrid film matrices versus the Ag-SPR absorption position.
$(\mathrm{RI}=1.475)$ to Ag-SGT037 $(\mathrm{RI}=1.710)$ due to the gradual increase of the high index Ti-component of the hybrid matrices (see table 2). As a consequence, deep yellow (Ag-SGT730), yellowish-orange, (AgSGT433), orange (Ag-SGT235), brownish-orange (Ag-SGT136) and orangish-brown (Ag-SGT037) coloured coatings on plastics and glass substrates are obtained. A systematic red-shifting of Ag-SPR position is therefore clearly established apparently due to the gradual increase of refractive indices of the matrices. Figure $3 \mathrm{~b}$ shows a plot of RI of the matrices versus Ag-SPR positions. It shows that the red-shifting can be best fitted following a polynomial fitting with an order equals to 2 .

Figure 4 shows the photo of final UV-treated coloured films deposited on PC (plastic) substrates. The photo clearly shows uniform colouration and systematic colour change due to increase of Ti-component leading to increase of RI index of the coating matrices. The transparency and uniform colouration of the films indicate that the structure of composite inorganic-organic hybrid matrices and distribution of embedded Ag nanoparticles are uniform.

The transmission electron microscopy (TEM) studies of the cured Ag-SGT730 (without Ti-component) and two representative Ti-containing samples (Ag-SGT433 and Ag-SGT037) were undertaken to characterize the in situ generated Ag nanoparticles in the hybrid film matrices. It can be noted here that the TEM of Ag-SGT730 film (without Ti-component) has been reported earlier by us ${ }^{12}$ and a part of that is reproduced in this work with some modification for comparison. The TEM of Ag-SGT730 and

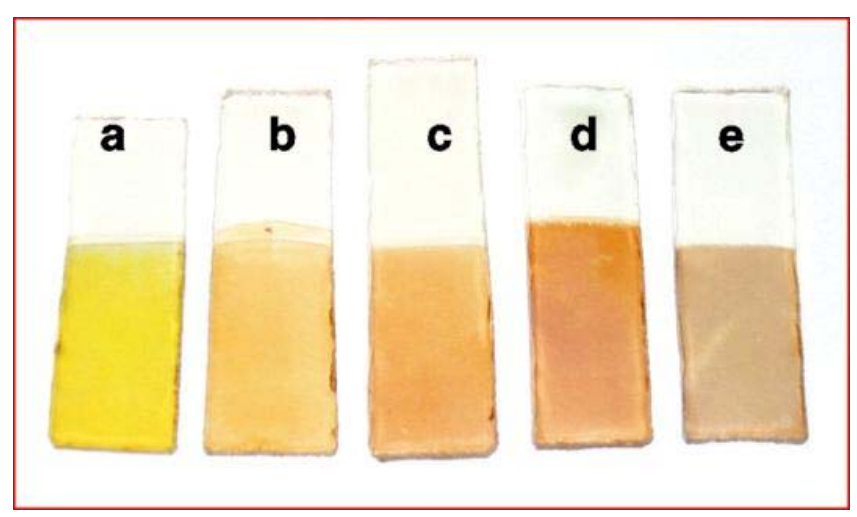

Figure 4. Photo shows Ag nanoparticle incorporated coloured hybrid films on polycarbonate substrates after thermal $\left(90^{\circ} \mathrm{C} / 1 \mathrm{~h}\right)$, and followed by UV curing with an energy equivalent to $5 \cdot 3 \pm 0 \cdot 1 \mathrm{~J} \mathrm{~cm}^{-1}$ : (a) Ag-SGT730, (b) Ag-SGT433, (c) Ag-SGT235, (d) Ag-SGT136 and (e) Ag-SGT037. 
other two representative Ti-containing films (AgSGT433 and Ag-SGT037) are presented in figure 5.

TEM of Ag-SGT730 film shows presence of mainly two types of nanoparticles (figure 5a); among these $90 \%$ (in number) are about $4 \mathrm{~nm}$ in size and remaining $10 \%$ are $12-20 \mathrm{~nm}$. The size distributions of $\mathrm{Ag}$ nanoparticles are also shown in figure $5 \mathrm{a}_{1}$. The high resolution image obtained from a big particle (figure
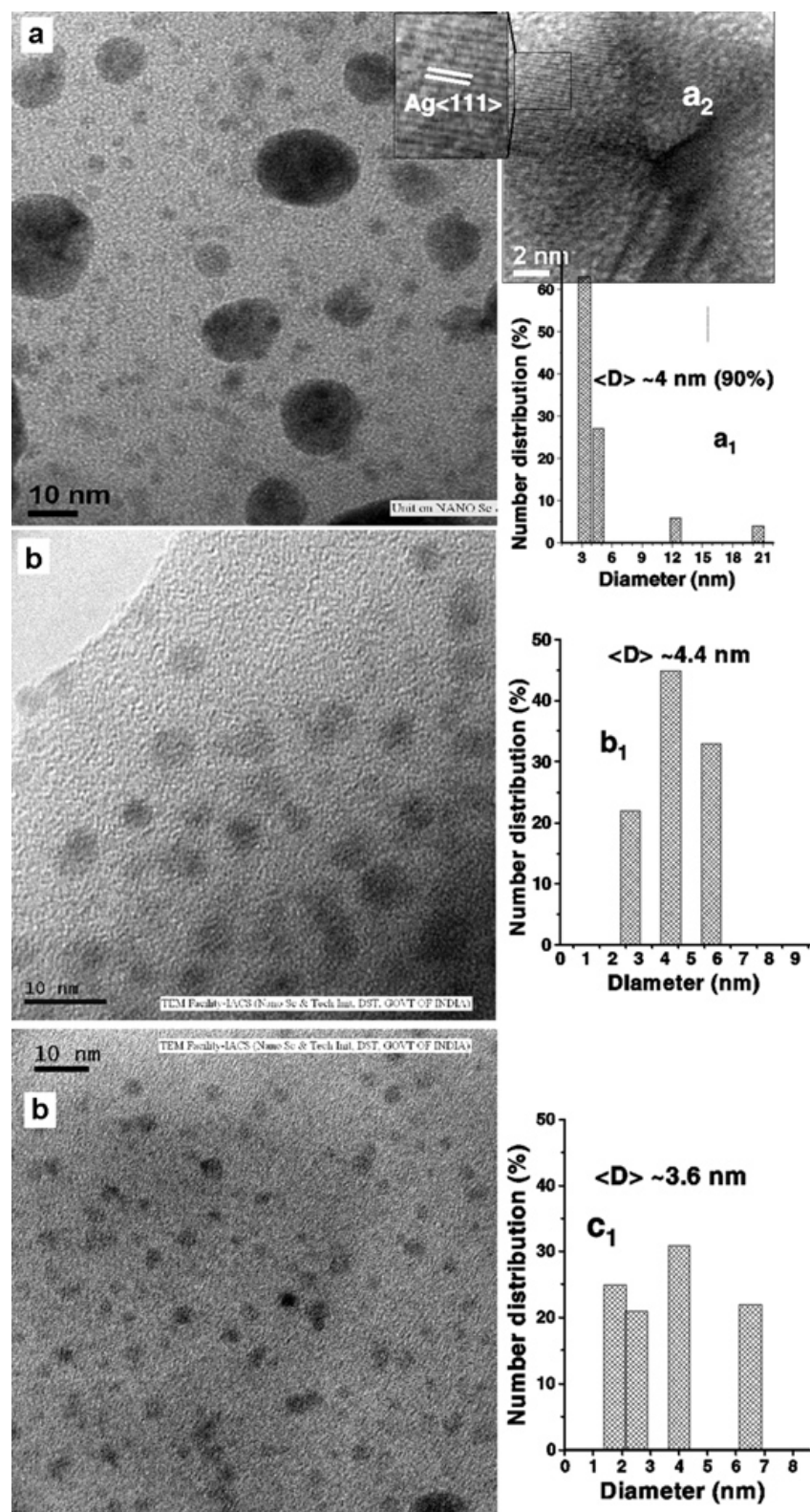

Figure 5. TEM image showing Ag nanoparticles embedded in the final UV-cured films: (a) Ag-SGT730 film; the size distributions and high resolution image of one bigger Ag nanoparticle are shown in $\mathrm{a}_{1}$ and $\mathrm{a}_{2}$ respectively, (b) Ag-SGT433 film; the size distribution is shown in $b_{1}$ and (c) Ag-SGT037 film; the size distribution is shown in $\mathrm{c}_{1}$.
$5 \mathrm{a}_{2}$ ) clearly shows characteristic $\mathrm{Ag}\langle 111\rangle$ lattice spacing (see the magnified view of the marked area). Second panel of figures $5\left(b\right.$ and $\left.b_{1}\right)$ shows the TEM image obtained from the Ag-SGT433 sample (b) and its particle size distributions $\left(b_{1}\right)$. Spherical $A g$ nanoparticles of average size distribution of $\langle\mathrm{D}\rangle$ $\sim 4.4 \mathrm{~nm}$ are found to be present in this sample. TEM of the highest Ti-containing sample AgSGT037 (figures 5c and $c_{1}$ ) also shows similar features, but in this case size of the Ag nanoparticles are little smaller $(\langle\mathrm{D}\rangle \sim 3 \cdot 6 \mathrm{~nm})$. It may also be noted here that no crystalline phases of titania is observed during TEM investigations. ${ }^{10}$ TEM study reveals the presence of some larger $(\sim 10 \%$ in number $)$ along with small Ag nanoparticles in case of Ag-SGT730 (figure 5a) whereas this feature is absent in the Ticontaining samples and only small nanoparticles are observed (see figures $5 \mathrm{~b}$ and c). We have previously observed coarsening of small Ag nanoparticles leading to the formation of larger nanoparticles in the case of Ag-SGT730. ${ }^{12}$ Therefore, it seems that the Ti-containing matrix is not favourable for such type of coarsening of Ag nanoparticles. This could be due to strong interaction of $\mathrm{Ag}$ with the titania compared to silica, resulting in restriction in movement of $\mathrm{Ag}$ in Ti-containing matrices.

Although some size variation and distributions of Ag nanoparticles are observed in these three cases as observed by TEM, it may be concluded here that this variation of size would not affect much on the Ag-SPR positions, ${ }^{12,13}$ as observed in their UVvisible spectra and colours. So, we may conclude that the systematic red-shifting of Ag-SPR positions are apparently controlled by the refractive index of the embedding coating matrices. It should be pointed out here that the shifting of Ag-SPR observed in this work is more than expectation. In an earlier work, ${ }^{15}$ we showed that when $\mathrm{Ag}$ nanoparticles of size $7 \pm 5 \mathrm{~nm}$ are embedded in a dielectric film matrix of $\mathrm{RI} \sim 1.71$, the composite film absorbs at about $434 \mathrm{~nm}$ due to Ag-SPR which is in agreement with the Mie theory. So in the present systems other effects like interference problems originating from the difference of RI values between the film matrices and substrates, nanoparticles' surface-matrix interaction (it may happen that the Ag nanoparticles are in close proximity to the high index Ticomponent), as well as plasmon coupling of the nanoparticles ${ }^{10}$ (it happens when nanoparticles remain very close to each other) might affect the SPR absorption position of the nanoparticles. 


\section{Conclusions}

Inorganic (silica-titania)-organic (polyethylene oxide) hybrid films of different refractive index values and the corresponding $\mathrm{Ag}$ nanoparticle incorporated films were synthesized. Keeping in view the application on plastic substrates the compositions and synthetic techniques were designed in such a way so that the hybrid films can be cured at low temperature $\left(\sim 90^{\circ} \mathrm{C}\right)$ in combination with UV treatment using a conveyor system. In situ generation of $\mathrm{Ag}$ nanoparticles in these refractive index controlled hybrid matrices yielded tunable coloured coatings. Our result shows that using this synthetic protocol, the position of Ag-SPR band in the visible wavelength region (419-597 nm) can be controlled easily and systematically by changing the equivalent silica/polyethylene oxide/titania mol ratios leading to the formation of variable refractive indices of the hybrid matrices, and as a result, tuning of colour is possible. This refractive index controlled as well as the coloured coatings could find technological applications in the development of abrasion resistant reflecting, antireflecting and coloured coatings on plastic substrates as well as nonlinear optical material.

\section{Acknowledgements}

Financial support from the Department of Science and Technology (DST), Government of India under National Nano Mission program is acknowledged. The authors thank the Director, Central Glass Ceramic Research Institute, Kolkata for encouragement.

\section{References}

1. Sachez C, Julián B, Belleville P and Popall M $2005 J$. Mater. Chem. 153559

2. Schottner G, Rose K and Posset U 2003 J. Sol-Gel Sci. and Technol. 2771

3. Schimdt H and Popall M 1990 in Sol-Gel Optics I (eds) J D Mackenzie and D R Ulrich (Washington: Proc. SPIE) p. 249

4. De G and Medda S K 2003 Ind. Pat. No. 196846

5. De G, Kundu D and Medda S K 2003 Ind. Pat. No. 202349

6. De G and Medda S K 2007 Ind. Pat. Appl. No. $0068 \mathrm{NF}$

7. Medda S K, Kundu D and De G 2003 J. Non-Cryst. Solids 318149

8. De G and Kundu D 2001 Chem. Mater. 134239

9. De G and Kundu D 2001 J. Non-Cryst. Solids 288221

10. De G and De S 2008 J. Phys. Chem. C112 10378

11. Medda S K and De G 2008 Ind. Eng. Chem. Res. (submitted)

12. De S and De G 2006 J. Mater. Chem. 163193

13. Medda S K, De S and De G 2005 J. Mater. Chem. 15 3278

14. De S and De G 2008 J. Nanosci. Nanotech. 83868

15. Gonella F, Mattei G, Mazzoldi P, Battaglin G, Quaranta A, De G and Montecchi M 1999 Chem. Mater. 11814

16. Innocenzi P, Brusatin G, Guglielmi M and Bertani R 1999 Chem. Mater. 114239

17. Dean K, Cook W D, Bruchill P and Zipper M 2001 Polymer 42, 3589

18. De G, Chatterjee A and Ganguli D 1990 J. Mater. Sci. Lett. 9845

19. Léaustic A, Babonneau F and Livage J 1989 Chem. Mater. 1240

20. Del Monte F, Cheben P, Grover C P and Mackenzie J D 1999 J. Sol-Gel Sci. and Technol. 1573

21. Colthup N B, Daly L H and Wiberley S E 1990 Introduction to infrared and Raman spectroscopy (San Diego: Academic Press Inc.) 3rd edn, p. 297

22. Smith A L 1960 Spectrochim. Acta 1687 